Check for updates

Cite this: RSC Adv., 2017, 7, 28506

Received 5th May 2017

Accepted 24th May 2017

DOI: $10.1039 / \mathrm{c} 7 \mathrm{ra05079h}$

rsc.li/rsc-advances

\section{A new method for fast statistical measurement of interfacial misfit strain around nano-scale semi- coherent particles}

\begin{abstract}
Liang Liang Song, ${ }^{\text {ab }}$ Shaojun $\mathrm{Liu}^{\mathrm{a}}$ and Xiaodong Mao (D) *a
An innovative diffraction contrast imaging method derived from Ashby-Brown contrast is presented for fast and statistical measurement of interfacial misfit strain around nano-sized semi-coherent particles. A correlation between nano-scale interfacial misfit strain and the fringe-like transmission electron microscopy (TEM) contrast lines was set up, by which interfacial misfit strain could be obtained by measuring the inter-spacings between the so-called "no-contrast" lines. The mechanism of the measurement lies on the symmetry of the strain field at specific orientations around semi-coherent particles due to the presence of misfit dislocations, which induces "no-contrast" lines on TEM images under proper two-beam conditions. A much lower average lattice misfit strain of $4 \%$, rather than $9.45 \%$ expected from lattice misfit between matrix and precipitate crystals, was revealed along $(02 \overline{2})_{\text {Matrix }}$ in austenitic oxide dispersion strengthened steel by this method, and was confirmed by geometric phase analysis (GPA) on high resolution transmission electron microscopy (HRTEM) images. This diffraction contrast imaging method is especially suitable for measuring misfit strain around particles that are smaller than $10 \mathrm{~nm}$, and is expected to bridge the gap between nano-scale interfacial structure and mechanical properties of materials that are strengthened by semi-coherent nano-particles.
\end{abstract}

\section{Introduction}

It is a long-lasting challenge to correlate microstructure with physical and mechanical properties for multi-phase materials, such as complex oxide systems, multilayered materials, dispersion strengthened composites, etc. Interfaces often determine macroscopic mechanical, physical, and chemical properties of these materials. ${ }^{1-5}$ It is widely recognized that, to design and to control macroscopic materials properties successfully, a fundamental understanding of the structure and chemistry of the interfaces is necessary. For engineering materials such as oxide dispersion strengthened alloys, the structure and interfacial misfit strain of the ceramic/metal (C/M) interface are of great importance to understand and predict the mechanical behaviors, owing to the extraordinary influence of the misfit strain on dislocation motion..$^{6-8}$ Lack of a fast and statistical quantitative measurement method has been a major obstacle to analyze the complex strain field at the nano-scale $\mathrm{C} /$ $\mathbf{M}$ interface. While the theories of metal and ceramic homophase interfaces (grain boundaries) are fairly well developed, heterophase $\mathbf{C} / \mathbf{M}$ interfaces are a relatively less well-studied subject. Experimentally the nano-scale $\mathrm{C} / \mathrm{M}$ interfaces have

${ }^{a}$ Key Laboratory of Neutronics and Radiation Safety, Institute of Nuclear Energy Safety Technology, Chinese Academy of Sciences, Hefei, Anhui, 230031, China. E-mail: xiaodong.mao@fds.org.cn

${ }^{b}$ University of Science and Technology of China, Hefei, Anhui, China been exclusively studied by HRTEM. ${ }^{9-15}$ However, statistical data on a large number of interfaces are needed for predicting the mechanical properties, which can hardly be accomplished. A fast and statistical method for data acquisition on a large number of interfaces is keenly needed. In this paper, such a method is presented that fast and statistical measurement on interfacial strain around semi-coherent particle could be achieved.

A misfit contrast of a coherent, spherical particle under a two-beam condition in TEM was quantified by Ashby and Brown. ${ }^{16}$ It indicates an undistorted vertical plane that runs right through the center of the particle. This absence of distortion causes a "line of no contrast" that runs through the image of the particle perpendicular to the active $\mathbf{g}$ vector. A simplified explanation is that, according to the Howie-Whelan equations, the amplitude $A_{\mathrm{g}}$ of a diffracted beam by a column of the matrix around the coherent particle is

$$
\begin{aligned}
A_{\mathrm{g}}= & \frac{i \pi}{\xi_{\mathrm{g}}} A_{0} \int_{0}^{t} \exp \\
& \times\left[-2 \pi i\left(s_{\mathrm{g}} z+\frac{3 K \delta r_{0}{ }^{3} x|\mathbf{g}|}{\left(3 K+\frac{2 E}{1+\nu}\right)\left[x^{2}+y^{2}+(v-z)^{2}\right]^{3 / 2}}\right)\right] \mathrm{d} z
\end{aligned}
$$

where $\xi_{\mathrm{g}}$ is the characteristic length and $s_{\mathrm{g}}$ is the deviation parameter for reflection $g, A_{0}$ is the amplitude of the direct 
beam, $x, y, z$ represent lattice displacements in the coordinate system, $t$ is the sample thickness, $K$ is the bulk modulus of particle, $\delta$ is the misfit between the unstrained lattices of particle and matrix, $r_{0}$ is the radius of the particle, $E$ and $v$ are the Young's modulus and Poisson's ration for the matrix, respectively. It can be seen from eqn (1) that, if $x=0$ ( $x$ is the lattice displacement parallel to $\mathbf{g}$ ), then $\mathbf{g} \cdots \mathbf{x}=0$, and the diffraction contrast of the feature is invisible.

An Ashby-Brown contrast does not apply to semi-coherent particles, where the elastic distortion around semi-coherent particles has no spherical symmetry. Fringes observed on semi-coherent and incoherent particles were normally explained by moiré fringes which are formed due to the overlapped images by two perfect crystals. ${ }^{17-22}$ However, as a semicoherent particle becomes smaller in size to several nanometers, the volume of a transitional zone of a distorted interface cannot be ignored, which may dominate the TEM image contrast. For instance, a 64 A-thick transitional zone was detected across a Fe $/ \mathrm{Y}_{2} \mathrm{O}_{3}$ interface. ${ }^{23}$ Therefore, the TEM image contrast of spherical precipitates with a size of around $10 \mathrm{~nm}$ or smaller should be preferably illustrated by an elastic strain field rather than moiré fringes. Precipitates of this size are of particular interest as they exhibit a high dispersion strengthening effect. ${ }^{24-26}$ For instance, Co-rich particles in $\mathrm{Cu}-\mathrm{Co}$ alloys, ${ }^{17}$ a GP-zone in $\mathrm{Al}$ base alloys,${ }^{24} \mathrm{NbC}$ nano-particles in $\mathrm{Nb}$ containing austenitic steel, ${ }^{25}$ and $\delta-\mathrm{Ni}_{2} \mathrm{Si}$ precipitates in $\mathrm{Cu}-\mathrm{Ni}-$ Si alloys. ${ }^{22}$ Recently, to meet the requirements of cladding tubes and other structural components of Gen. IV fission reactors, oxide dispersion strengthened (ODS) steel has attracted much attention. $^{\text {20,21,26-32 }}$ Oxide particles with sizes smaller than $10 \mathrm{~nm}$ are uniformly distributed in a steel matrix to impede the dislocation motion and attract irradiation induced point defects, reaching a high creep strength and good irradiation resistance. ${ }^{\mathbf{2 6 , 3 1 , 3 3}}$ Due to a large difference in lattice parameters between oxides and metals or different crystal structures, interfaces between oxide particles and alloy matrix tend to be semi-coherent, which was frequently observed in oxide dispersion strengthened steel..$^{20,21,33-38}$ Fringes observed in these studies were explained as moiré fringes, and the oxide particles were identified to be $\mathrm{Y}_{2} \mathrm{O}_{3}, \mathrm{Y}_{2} \mathrm{Ti}_{2} \mathrm{O}_{7}, \mathrm{YAlO}_{3}$, and $\mathrm{Y}_{4} \mathrm{Zr}_{3} \mathrm{O}_{12}$ of around $5 \mathrm{~nm}$ in diameter and have certain orientation relationships (ORs) with the matrix. ${ }^{20,21,33,35,36}$ Considering a 64 A-thick transitional zone across a $\mathrm{Fe} / \mathrm{Y}_{2} \mathrm{O}_{3}$ interface, the whole particle with a diameter of $5 \mathrm{~nm}$ and a matrix shell around the particle with a thickness of around $3 \mathrm{~nm}$ is within the transitional zone. Explanation by moiré fringes might be misleading because the whole image formation volume is distorted. The Ashby-Brown theory could be expanded to semi-coherent spherical precipitates by introducing stacked misfit dislocation loops on the precipitate/matrix interfaces. An elastic strain field around coherent and semi-coherent precipitates in a matrix has been intensively studied by experimental measurements and theoretical calculations and simulations. ${ }^{39-45}$ Previous study has shown that the elasticity problem of a transformed inclusion constrained in an infinite matrix could be solved by considering a dislocation cage made of uniformly stacked dislocation loops. ${ }^{46}$ If we consider that misfit dislocations are formed at the semi-coherent interface, the diffraction contrast of semi-coherent particles can be illustrated by a simple schematic configuration of the lattice displacement around the particles. The selection and valid property prediction of structural materials is very important to the safety of the reactors, and have great influence on thermal efficiency. ${ }^{47,48}$ Understanding the correlation between microstructure and mechanical properties of materials such as ODS steel will be of great significance for nuclear energy development.

The concepts of a fully coherent particle with a single 'nocontrast' line with a spherically symmetrical strain field in Ashby and Brown's paper and a semi-coherent particle with misfit dislocation loops showing multiple 'no-contrast' lines are illustrated in Fig. 1a and b. Misfit dislocations at the interfaces are edge dislocations with an identical Burgers vector, and are parallel to each other (Fig. 1b). The strain field around an edge dislocation is symmetrical about the extra half-plane of atoms. Therefore, the repelling stress is offset at the middle of two neighboring parallel edge dislocations with the same Burgers vector (Fig. 1c). Because the angle $(\theta)$ between two misfit dislocations on a spherical precipitate is always smaller than $45^{\circ}$ (as indicated in Fig. 1d), they repel each other. Thus, we can find a plane between the two parallel misfit dislocations where the overall strain component $\left(\mathbf{R}_{x}\right)$ along $\mathbf{g}$ is zero (thus $\mathbf{g} \cdot \mathbf{R}_{x}=0$ ). Since such a pair of perfectly matched planes exists between every two misfit dislocations, there will be $n-1$ 'no-contrast' lines ( $n$ is the number of misfit dislocations), as illustrated in Fig. 1b. This concept is applied to investigate $\mathrm{Y}_{2} \mathrm{Ti}_{2} \mathrm{O}_{7}$ particles in an austenitic matrix. It will be shown that a strain field can ideally explain the contrast of semi-coherent $\mathrm{Y}_{2} \mathrm{Ti}_{2} \mathrm{O}_{7}$ particles, and moiré fringe explanation will not stand for this particular case.

\section{Experiment}

The austenitic ODS steel in this study has a nominal composition of $\mathrm{Fe}$ (bal.) $-17 \mathrm{Cr}-12 \mathrm{Ni}-2.5 \mathrm{Mo}-0.3 \mathrm{Ti}-0.3 \mathrm{Y}_{2} \mathrm{O}_{3}$ in $\mathrm{wt} \%$. The fabrication processes include mechanical alloying (MA) of prealloyed powder with $0.3 \% \mathrm{Y}_{2} \mathrm{O}_{3}$, consolidation of $\mathrm{MA}$ powder by hot isostatic pressing (HIP) at $1150{ }^{\circ} \mathrm{C}$ for $4 \mathrm{~h}$, hot rolling of the HIP sample at $1200{ }^{\circ} \mathrm{C}$ with a total reduction ratio of $50 \%$, and finally solution heat treated at $1150{ }^{\circ} \mathrm{C}$ for 1 hour, followed by air cooling.

TEM analyses were conducted at $200 \mathrm{kV}$ by JEOL FE2100F HRTEM equipped with a Si-floating EDS. Electron beam transparent thin foil samples were prepared by standard procedures including slicing, grinding and polishing. The final thinning was performed by jet-polishing at $20 \mathrm{~V}$ and $253 \mathrm{~K}$ with the a solution of 5 vol\% perchloric acid and 95 vol\% methanol. Carbon extraction replica samples of the nano-sized oxide particles in the ODS steel sample were also prepared and observed under TEM to obtain more accurate EDS analyses on particle composition and statistical analysis of the particle size distribution by excluding the contrast deterioration due to the matrix. Carbon extraction replica samples were prepared from the electro-polished and etched ODS steel sample surface. The surface was etched by a solution of $2 \% \mathrm{HF}-2 \% \mathrm{HNO}_{3}-96 \% \mathrm{H}_{2} \mathrm{O}$. 

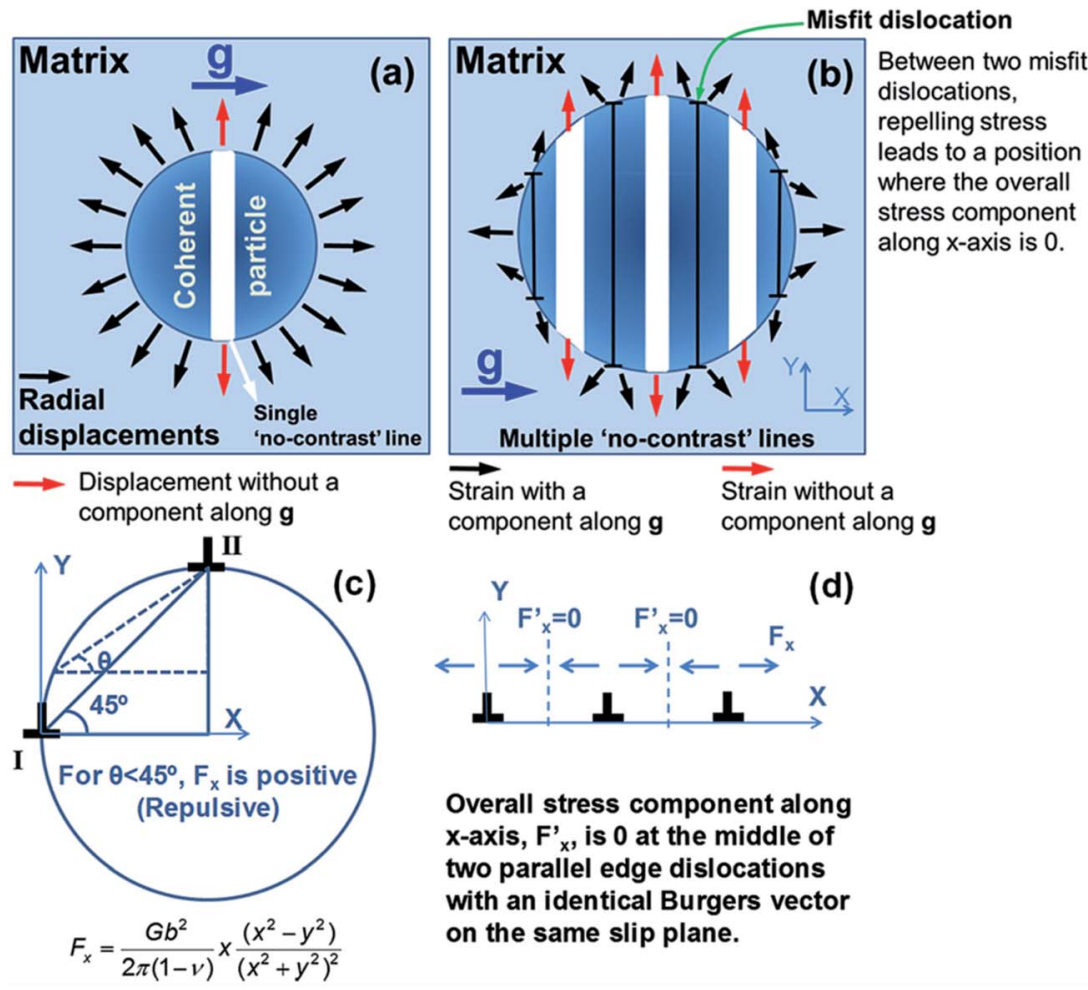

Overall stress component along $x$-axis, $F_{x}$, is 0 at the middle of two parallel edge dislocations with an identical Burgers vector on the same slip plane.

Fig. 1 Schematic strain field around (a) a coherent spherical particle, (b) a semi-coherent spherical particle in an infinite isotropic matrix, (c) repelling force between parallel edge dislocations of an identical burgers vector, and (d) geometry of edge-type misfit dislocations around a semi-coherent spherical particle.

\section{Results and discussion}

The austenitic ODS steel sample shows ultrafine-grained microstructure, with an average grain size of around $300 \mathrm{~nm}$, as shown in Fig. 2a. Annealing twins account for a high fraction of high angle grain boundaries. Nano-sized particles with a very high number density are uniformly distributed in the steel matrix, as shown in Fig. 2b. Fig. 2c shows images of nanoparticles taken from the carbon extraction replica sample. Particles are spherical in shape, and have relatively uniform sizes, ranging from around $3 \mathrm{~nm}$ to $30 \mathrm{~nm}$. The average size of particles is around $5 \mathrm{~nm}$. EDS analyses indicated that these particles are $\mathrm{Y}-\mathrm{Ti}-\mathrm{O}$ particles. Selected area diffraction (SAD) and nano-beam electron diffraction (NBED) have demonstrated that these $\mathrm{Y}-\mathrm{Ti}-\mathrm{O}$ particles are $\mathrm{Y}_{2} \mathrm{Ti}_{2} \mathrm{O}_{7}$ with a $\mathrm{FCC}$ crystal structure, and the orientation relationship (OR) between $\mathrm{Y}_{2} \mathrm{Ti}_{2} \mathrm{O}_{7}$ particles and the austenitic matrix $\operatorname{was}(\overline{2} 20)_{\mathrm{Y}_{2} \mathrm{Ti}_{2} \mathrm{O}_{7}} / /$ $(200)_{\text {Matrix }}$, and $(\overline{3} \overline{3} 1)_{\mathrm{Y}_{2} \mathrm{Ti}_{2} \mathrm{O}_{7}} / /(0 \overline{2} 2)_{\text {Matrix }}{ }^{49}$ The $\mathrm{Y}_{2} \mathrm{Ti}_{2} \mathrm{O}_{7}$ particles are semi-coherent with the matrix, with undistorted misfits of $0.86 \%$ along $(200)_{\text {Matrix }}$ and $9.45 \%$ along $(0 \overline{2} 2)_{\text {Matrix }}$. It was also demonstrated that parallel planes could only be obtained in these two directions. All other lattice planes between the oxide and matrix were tilted by small angles.

Fig. 3a shows a typical image of particles with single nocontrast lines running through particle centers perpendicular to the active $\boldsymbol{g}$ vector, $\mathbf{g}_{200}$, and Fig. $3 \mathrm{~b}$ shows the same area under $\mathbf{g}_{02 \overline{2}}$. Mostly, 2 or 3 no-contrast lines perpendicular to $\mathbf{g}_{02 \overline{2}}$ can be seen in a particle image, showing a lobe-lobe morphology. This contrast difference can be understood by considering that misfits along $\{200\}$ and $\{022\}$ planes are
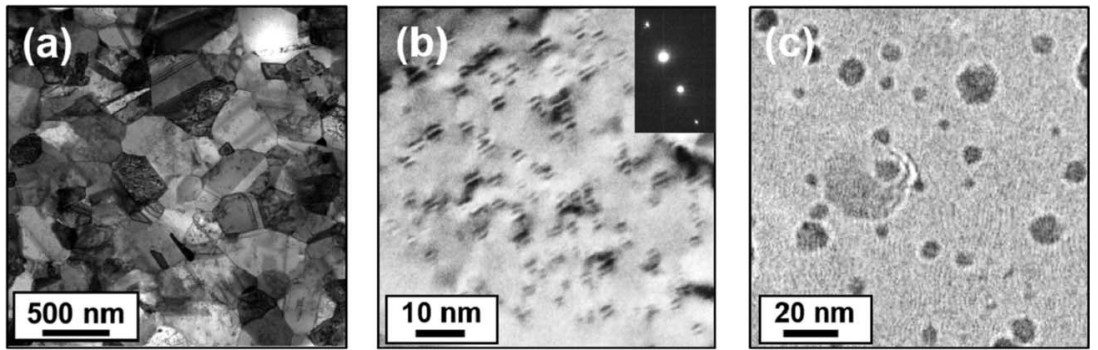

Fig. 2 (a) Microstructure of the austenitic ODS steel, (b) nano-sized particles in the matrix, and (c) image of nano-sized particles from a carbon extraction replica sample. 


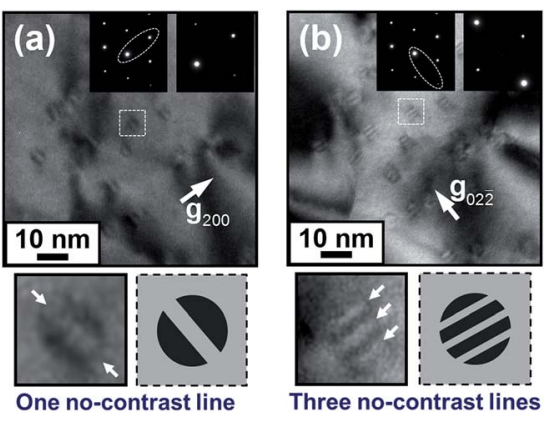

Fig. 3 Ashby-Brown contrast of $\mathrm{Y}_{2} \mathrm{Ti}_{2} \mathrm{O}_{7}$ particles under different two-beam conditions, (a) $\mathrm{g}_{200}$, (b) $\mathrm{g}_{022}$.

different. A misfit of $0.86 \%$ along (200) Matrix $_{\text {requires } 116 \text { planes }}$ of $(200)_{\text {Matrix }}$ to accommodate a misfit dislocation, which corresponds to a distance of $20.9 \mathrm{~nm}$ (116 times $0.18 \mathrm{~nm}$ ). This distance is larger than the size of the $\mathrm{Y}_{2} \mathrm{Ti}_{2} \mathrm{O}_{7}$ oxide particles in the image. No misfit dislocation can be formed at the interface along the (200) planes of the matrix, and the diffraction condition under $\mathbf{g}_{200}$ is identical with that of a coherent spherical particle. For $(02 \overline{2})_{\text {Matrix }}$ planes, however, a lattice misfit of $9.45 \%$ means that a misfit dislocation should be formed for every 10 or 11 planes of $(02 \overline{2})_{\text {Matrix, which corre- }}$ sponds to a distance between misfit dislocations of $11 \times 1.2728$ $=14 \AA\left(d_{022}=1.2728 \AA\right)$. For particles with sizes of $3 \mathrm{~nm}, 4 \mathrm{~nm}$, and $5 \mathrm{~nm}$, there will be 2, 2, and 3 misfit dislocations, respectively, which are evident in Fig. 3b. Therefore, semi-coherent $\mathrm{Y}_{2} \mathrm{Ti}_{2} \mathrm{O}_{7}$ particles exhibit different numbers of no-contrast lines under different two-beam conditions owing to the lattice misfit variations along different planes.

However, the fringes shown Fig. $3 \mathrm{~b}$ indicate that interspacings between no-contrast lines are mostly larger than the calculated value of $1.4 \mathrm{~nm}$, and show different values for different particles. Since all of these particles are identified to be the same $\mathrm{Y}_{2} \mathrm{Ti}_{2} \mathrm{O}_{7}$ particles with the same orientation, this phenomenon cannot be explained by the moiré fringes. Considering that a lattice distortion occurs to reduce the interface stress, the actual $d_{(02 \overline{2})}$ of the austenite matrix can increase, leading to a smaller lattice misfit at the interface and thus a larger misfit dislocation gap. The relaxation of the interfacial misfit strain and the corresponding broadening of inter-spacing between misfit dislocations can be seen in Fig. 4. Fig. 4a shows diffraction contrast images of particles under $\mathbf{g}_{02 \overline{2}}$, while Fig. 4b exhibits misfit dislocations at the interfaces of a typical particle. It can be seen that the inter-spacing between two neighboring misfit dislocations is around $2.8 \mathrm{~nm}$, being far larger than the calculated value of $1.4 \mathrm{~nm}$, indicating large extent of relaxation of the misfit strain at the interface. An interspacing of $2.8 \mathrm{~nm}$ between no-contrast lines corresponds to a distance of $22 \times d_{\{022\} \text { Matrix }}$ (without lattice distortion). The inter-planar spacing between $(02 \overline{2})_{\text {Matrix }}$ planes at the oxide/ matrix interface after a lattice distortion by a misfit strain comes to be $0.1217 \mathrm{~nm}(2.8 \mathrm{~nm} / 23)$. The lattice misfit at the interface thus becomes $4.54 \%$, compared to $9.45 \%$ without a lattice distortion, showing a reduction of the lattice misfit at the interface by up to $51.9 \%$ due to the lattice distortion. It indicates that the lattice misfit relaxation around semi-coherent interface may play a dominant role in determining the mechanical behaviors.

Above measurement on interfacial misfit strain is consistent with the HRTEM image measurement. Quantitative measurement of lattice displacement and strain map around a semicoherent $\mathrm{Y}_{2} \mathrm{Ti}_{2} \mathrm{O}_{7}$ particle was generated by the GPA method on a HRTEM image, as shown in Fig. 5. An introduction to the GPA method can be found in ref. 50. It can be seen that an average lattice displacement of around $4 \%$ along $[02 \overline{2}]$ direction is present in the matrix surrounding the particle, being consistent with the results from the diffraction contrast measurement on the inter-spacings between no-contrast lines. It shall be noted that the strain field was affected by the amorphous edge so that the strain was smaller as the particle was near to the sample edge. The volume of the matrix around the $\mathrm{Y}_{2} \mathrm{Ti}_{2} \mathrm{O}_{7}$ particle with obvious lattice displacement is comparable or larger than the particle volume itself, indicating a strong interfacial strain, which may contribute to the mechanical strength by strain hardening. It also indicates that a lattice distortion exclusively occurred in the matrix, while
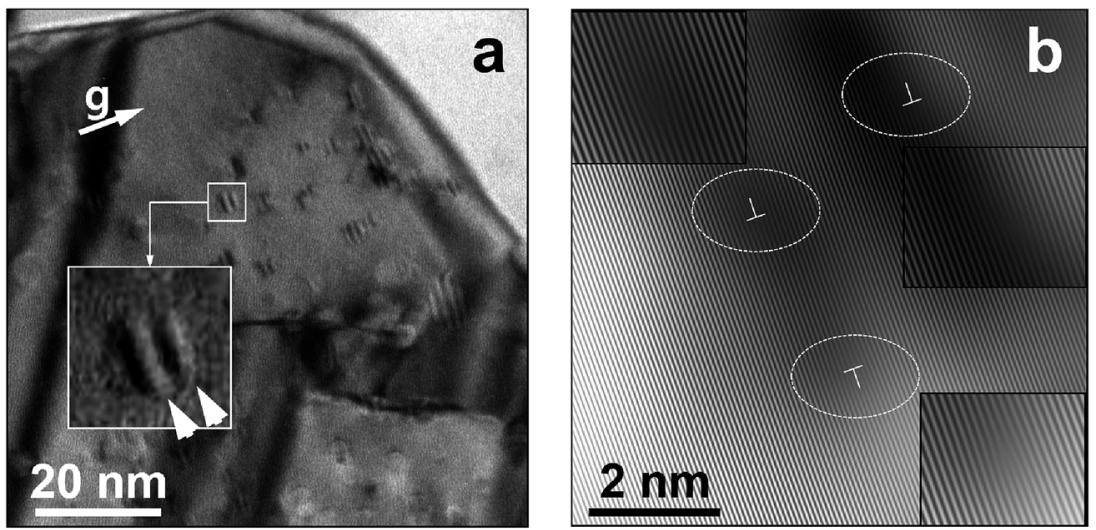

Fig. 4 (a) Multiple no-contrast lines on semi-coherent $\mathrm{Y}_{2} \mathrm{Ti}_{2} \mathrm{O}_{7}$ particles under $\mathrm{g}_{022}$ (b) HRTEM image of the misfit dislocations at the oxide/ matrix interface. 

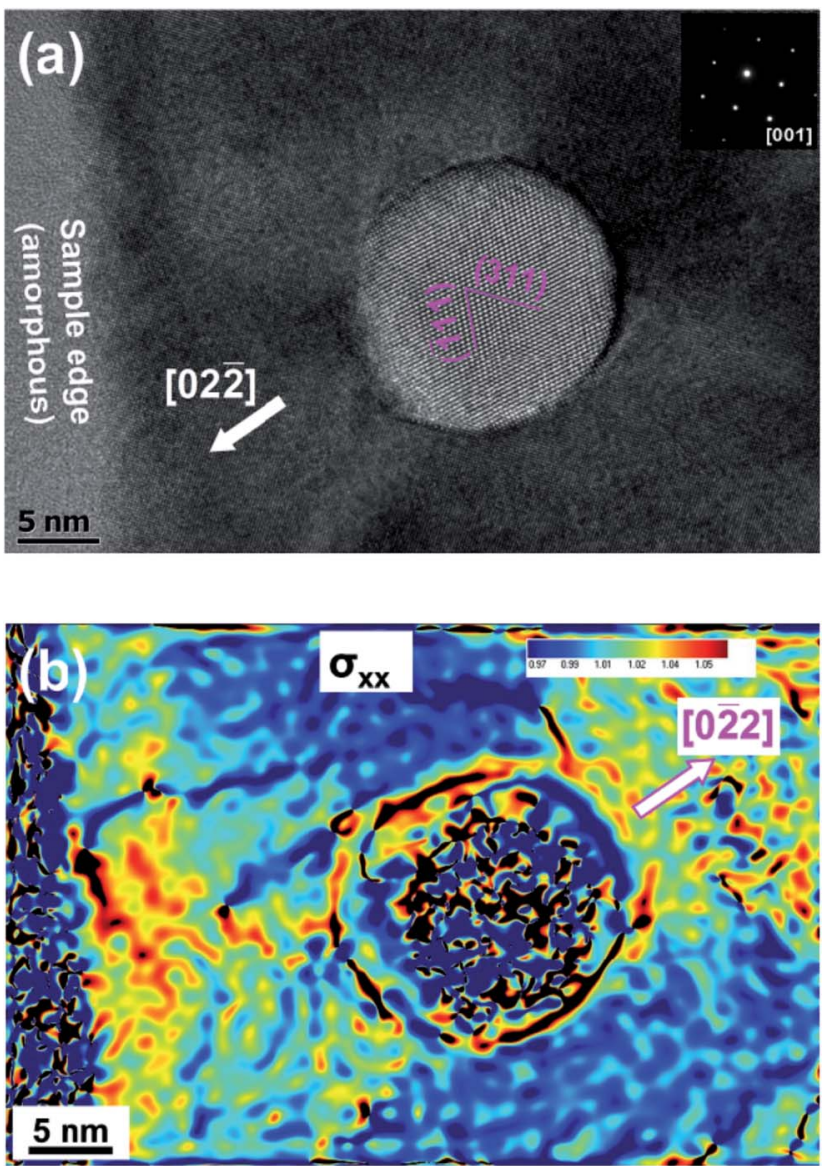

Fig. 5 (a) A HRTEM image of a semi-coherent $\mathrm{Y}_{2} \mathrm{Ti}_{2} \mathrm{O}_{7}$ particle, (b) strain map generated by the GPA method from (a).

distortion in the particle is rather small or even ignorable. This occurs due to the fact that Young's modulus of $\mathrm{Y}_{2} \mathrm{Ti}_{2} \mathrm{O}_{7}$ is much larger than the Fe base matrix. ${ }^{51}$

Compared to the measurement of interfacial misfit strain by HRTEM, the diffraction contrast method in this work has the advantage of fast statistical measurement on a large number of particles by a single TEM image, as illustrated in Fig. 6. Interfacial misfit strain of most particles in Fig. 6 can be readily obtained by measuring the inter-spacings between "nocontrast" lines, which can also distinguish the difference in interfacial strain among different particles. For instance, it could be seen from Fig. 6 that interfacial strain varies from 3.3\% to $4.9 \%$ among particles, possibly due to the local microstructural features such as dislocations. Fine particles $(<3 \mathrm{~nm})$ that are marked by dashed circles exhibited single no-contrast lines, indicating that misfit dislocations were not formed due to the strain relaxation.

Previously the "no-contrast" lines have been illustrated as moire fringes, which are formed when two sets of lattices are overlapped. However, moiré fringes may not apply to semicoherent particles that are smaller than $10 \mathrm{~nm}$, as the interfacial misfit strain is dominating the two-beam contrast TEM images. For example, by overlapping $(\overline{1} 1 \overline{1})_{\text {Matrix }}$ and $(\overline{5} \overline{1} 1)_{\mathrm{Y}_{2} \mathrm{Ti}_{2} \mathrm{O}_{7}}$ planes and rotating around $[011]_{\text {Matrix }}$ by $2.5^{\circ}$, moiré fringes

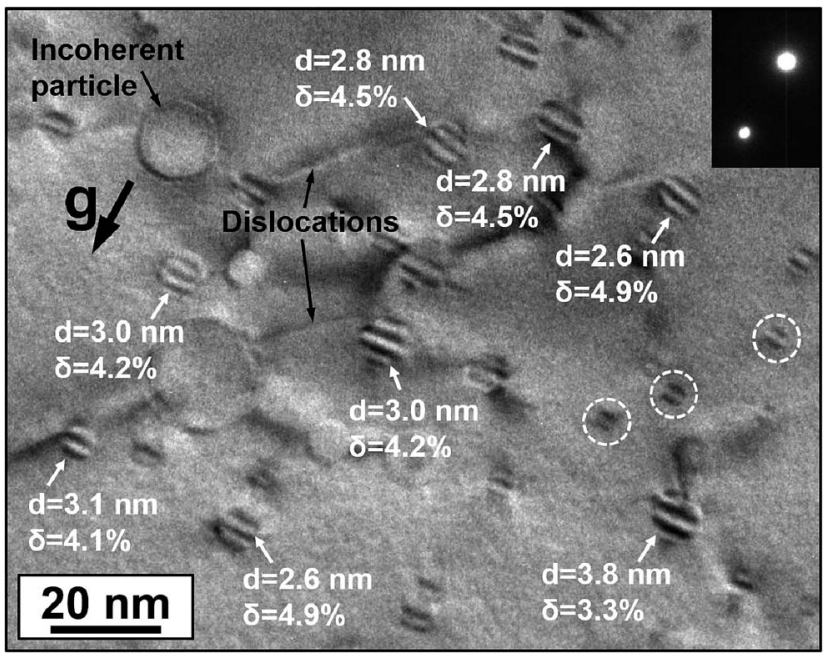

Fig. 6 Measurement of interfacial misfit strain of a large number of semi-coherent particles by a single two-beam ( $\mathbf{g}_{022}$ ) condition TEM image.

should be observable on particles with sizes of around $5 \mathrm{~nm}$ without interface lattice distortion (Fig. 7a). The moiré fringe spacing is about $2.5 \mathrm{~nm}$ and the angle between the moiré fringes and $(\overline{1} 1 \overline{1})_{\text {Matrix }}$ planes is about $30.2^{\circ}$ according to eqn (2) and (3)..$^{52}$ The theoretical moire fringes according to the OR between the $\mathrm{Y}_{2} \mathrm{Ti}_{2} \mathrm{O}_{7}$ lattice and matrix without distortion are illustrated in Fig. 7a. The sample was then tilted to be under $\mathbf{g}_{\overline{1} \overline{1} 1}$, where interference lattice planes of $(\overline{1} 1 \overline{1})_{\text {Matrix }}$ and $(\overline{5} 11)_{\mathrm{Y}_{2} \mathrm{Ti}_{2} \mathrm{O}_{7}}$ are edge on. In this study, no such fringes on fine particles were observed under $\mathbf{g}_{\overline{1} \mathbf{1} 1}$ (Fig. $7 \mathrm{~b}$ ). Several other twobeam conditions such as $\mathbf{g}_{112}, \mathbf{g}_{(13 \overline{1})}$ were investigated, and no fringes were observed. It shows that a moire fringe explanation does not apply here. Moire fringes were not formed under these conditions due to the fact that the image contrast is dominated by the distorted interface instead of perfect crystals of $\mathrm{Y}_{2} \mathrm{Ti}_{2} \mathrm{O}_{7}$ and the austenite matrix. Tilting by $2.5^{\circ}$ between (111i) $)_{\text {Matrix }}$ and $(\overline{5} \overline{1} 1)_{\mathrm{Y}_{2} \mathrm{Ti}_{2} \mathrm{O}_{7}}$ planes indicates that the strain field is asymmetrical under $\mathbf{g}_{\overline{1} \overline{1} 1}$. The combined lattice displacement parallel to $\mathbf{g}_{\overline{1} \overline{1} 1}$ is never $(x \neq 0)$, and $\mathbf{g} \cdot R \neq 0$ according to eqn (1).

$$
d_{\mathrm{M}}=\frac{d_{1} d_{2}}{\sqrt{d_{1}^{2}+d_{2}^{2}-2 d_{1} d_{2} \cos \theta}}=2.5 \mathrm{~nm}
$$
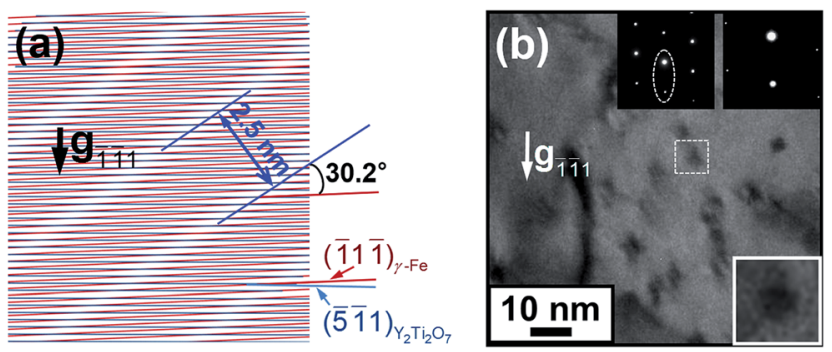

Fig. 7 (a) Moiré fringes formed by overlapping undistorted $(111)_{\text {Matrix }}$ and $(511)_{\mathrm{Y}_{2} \mathrm{Ti}_{2} \mathrm{O}_{7}}$ planes and rotating by $2.5^{\circ}$; (b) no such moiré fringes were observed on the TEM images taken under the condition. 


$$
\theta_{(\overline{1} 1 \overline{1}) \gamma-\mathrm{M}}=\arcsin \left(\frac{d_{1} \sin 2.5^{\circ}}{\sqrt{d_{1}^{2}+d_{2}^{2}-2 d_{1} d_{2} \cos 2.5^{\circ}}}\right)=30.2^{\circ}
$$

where $d_{1}$ and $d_{2}$ are the interplanar spacing of crystallographic plane 1 and plane 2, respectively. And $d_{\mathrm{M}}$ is the interplanar spacing between moiré fringes, $\theta$ is the angle between plane 1 and moiré fringes.

\section{Conclusion}

This study gives a fast quantitative method for measurement of the interfacial strain around semi-coherent particles that are smaller than $10 \mathrm{~nm}$. The underlying mechanism lies on the formation of "no-contrast" lines due to the symmetry of the interfacial strain field around semi-coherent particles under proper two-beam conditions. Application of this method on semi-coherent $\mathrm{Y}_{2} \mathrm{Ti}_{2} \mathrm{O}_{7}$ particles in austenitic ODS steel revealed an substantial decrease of the misfit strain by $51.9 \%$ compared to that estimated from undistorted lattices. This method is expected to contribute to the correlation between microstructure and mechanical strength of alloys that are strengthened by semi-coherent particles.

\section{Acknowledgements}

The authors would like to thank the great help from the other members of FDS team. This work was supported by the One Hundred Talents Program of Chinese Academy of Sciences and the National Magnetic Confinement Fusion Science Program of China with Grant No. 2013GB108005.

\section{References}

1 S. B. Sinnotta and E. C. Dickey, Mater. Sci. Eng., R, 2003, 43, 1-59.

2 J. Chakhalian, J. W. Freeland, H.-U. Habermeier, G. Cristiani, G. Khaliullin, M. van Veenendaal and B. Keimer, Science, 2007, 318, 1114-1117.

3 J. Mannhart and D. G. Schlom, Science, 2010, 327, 1607-1611.

4 H. Y. Hwang, Y. Iwasa, M. Kawasaki, B. Keimer, N. Nagaosa and Y. Tokura, Nat. Mater., 2012, 11, 103-113.

5 F. Huang, B. Cho, H.-S. Chung, S. B. Son, J. H. Kim, T.-S. Bae, H. J. Yun, J. I. Sohn, K. H. Oh, M. G. Hahm, J. H. Park and W.-K. Hong, Nanoscale, 2016, 8, 17598-17607.

6 C. Capdevila, M. M. Aranda, R. Rementeria, J. Chao, E. Urones-Garrote, J. Aldazabal and M. K. Miller, Acta Mater., 2016, 107, 27-37.

7 A. Hirata, T. Fujita, Y. R. Wen, J. H. Schneibel, C. T. Liu and M. W. Chen, Nat. Mater., 2011, 10, 922-926.

8 P. Luches, V. Bellini, S. Colonna, L. Di Giustino, F. Manghi, S. Valeri and F. Boscherini, Phys. Rev. Lett., 2006, 96, 106106. 9 F. Ernst, Mater. Sci. Eng., R, 1995, 14, 97-156.

10 D. A. Shashkov, M. F. Chisholm and D. N. Seidman, Acta Mater., 1999, 47, 3939-3951.
11 P. L. Galindo, S. Kret, A. M. Sanchez, J.-Y. Laval, A. Yáñez, J. Pizarro, E. Guerrero, T. Ben and S. I. Molina, Ultramicroscopy, 2007, 107, 1186-1193.

12 S.-C. Wang, M.-Y. Lu, A. Manekkathodi, P.-H. Liu, H.-C. Lin, W.-S. Li, T.-C. Hou, S. Gwo and L.-J. Chen, Nano Lett., 2014, 14, 3241-3246.

13 N. Homonnay, K. J. ÓShea, C. Eisenschmidt, M. Wahler, D. A. MacLaren and G. Schmidt, ACS Appl. Mater. Interfaces, 2015, 7, 22196-22202.

14 N. Li, S. K. Yadav, Y. Xu, J. A. Aguiar, J. K. Baldwin, Y. Q. Wang, H. M. Luo, A. Misra and B. P. Uberuaga, Sci. Rep., 2017, 7, 40148.

15 J. L. Du, L. Y. Zhang, E. G. Fu, X. Ding, K. Y. Yu, Y. G. Wang, Y. Q. Wang, J. K. Baldwin, X. J. Wang and P. Xu, Appl. Surf. Sci., 2017, 410, 585-592.

16 M. F. Ashby and L. M. Brown, Philos. Mag., 1963, 8, 10831103.

17 V. A. Philips, Acta Metall., 1966, 14, 1533-1547.

18 P. H. Pumphery and J. W. Edington, Acta Metall., 1974, 22, 89-94.

19 I. Ishida and M. Kiritani, Acta Metall., 1988, 36, 2129-2139.

20 P. Dou, A. Kimura, T. Okuda, M. Inoue, S. Ukai, S. Ohnuki,

T. Fujisawa and F. Abe, Acta Mater., 2011, 59, 992-1002.

21 J. Ribis and Y. de Carlan, Acta Mater., 2012, 60, 238-252.

22 T. Hu, J. H. Chen, J. Z. Liu, Z. R. Liu and C. L. Wu, Acta Mater., 2013, 61, 1210-1219.

23 E. B. Watkins, A. Kashinath, P. Wang, J. K. Baldwin, J. Majewski and M. J. Demkowicz, Appl. Phys. Lett., 2014, 105, 041601.

24 X. Fan, D. Jiang, Q. Meng, Z. Lai and X. Zhang, Mater. Sci. Eng., A, 2006, 427, 130-135.

25 Y. Yamamoto, M. P. Brady, Z. P. Lu, P. J. Maziasz, C. T. Liu, B. A. Pint, K. L. More, H. M. Meyer and E. A. Payzant, Science, 2007, 20, 433-436.

26 G. R. Odette, M. J. Alinger and B. D. Wirth, Annu. Rev. Mater. Res., 2008, 38, 471-503.

27 A. Kimura, R. Kasada, A. Kohyama, H. Tanigawa, T. Hirose, K. Shiba and R. L. Klueh, J. Nucl. Mater., 2007, 367, 60-67.

28 M. J. Alinger, G. R. Odette and D. T. Hoelzer, Acta Mater., 2009, 57, 392-406.

29 Y. de Carlan, J. L. Bechade, P. Dubuisson, J. L. Seran, P. Billot, A. Bougault, T. Cozzika, S. Doriot, D. Hamon, J. Henry, M. Ratti, N. Lochet, D. Nunes, P. Olier, T. Leblond and M. H. Mathon, J. Nucl. Mater., 2009, 386, 430-432.

30 J. H. Schneibel, C. T. Liu, M. K. Miller, M. J. Mills, P. Sarosi, M. Heilmaierc and D. Sturm, Scr. Mater., 2009, 61, 793-796.

31 P. Dou, A. Kimura, R. Kasada, T. Okuda, M. Inoue, S. Ukai, S. Ohnuki, T. Fujisawa and F. Abe, J. Nucl. Mater., 2013, 442, S95-S100.

32 A. Kashinath, A. Misra and M. J. Demkowicz, Phys. Rev. Lett., 2013, 110, 086101.

33 A. Ramar, N. Baluc and R. Schäublin, J. Nucl. Mater., 2009, 386, 515-519.

34 L. Hsiung, M. Fluss, S. Tumey, J. Kuntz, B. El-Dasher, M. Wall, B. Choi, A. Kimura, F. Willaime and Y. Serruys, J. Nucl. Mater., 2011, 409, 72-79. 
35 Y. Miao, K. Mo, B. Cui, W.-Y. Chen, M. K. Miller, K. A. Powers, V. McCreary, D. Gross, J. Almer, I. M. Robertson and J. F. Stubbins, Mater. Charact., 2015, 101, 136-143.

36 S. Y. Zhong, J. Ribis, T. Baudin, N. Lochet, Y. de Carlan, V. Klosek and M. H. Mathon, J. Nucl. Mater., 2014, 452, 359-363.

37 H. Oka, M. Watanabe, N. Hashimoto, S. Ohnuki, S. Yamashita and S. Ohtsuka, J. Nucl. Mater., 2013, 442, 164-168.

38 X. Mao, T. K. Kim, S. S. Kim, Y. S. Han and J. Jang, J. Nucl. Mater., 2015, 461, 329-335.

39 D. Mukherji, R. Gilles, B. Barbier, D. Del Genovese, B. Hasse, P. Strunz, T. Wroblewski, H. Fuess and J. Rösler, Scr. Mater., 2003, 48, 333-339.

40 A. G. Khachaturyan, S. Semenovskaya and T. Tsakalakos, Phys. Rev. B: Condens. Matter Mater. Phys., 1995, 52, 15909.

41 S. Onaka, T. Fujii and M. Kato, Mech. Mater., 1995, 20, 329336.

42 A. Kiris and E. Inan, Int. J. Solids Struct., 2006, 43, 4720-4738.
43 C. Shen, J. P. Simmons and Y. Wang, Acta Mater., 2006, 54, 5617-5630.

44 Y. Gao, H. Liu, R. Shi, N. Zhou, Z. Xu, Y. M. Zhu, J. F. Nie and Y. Wang, Acta Mater., 2012, 60, 4819-4832.

45 A. J. Vattré and M. J. Demkowicz, Acta Mater., 2015, 82, 234243.

46 Y. Q. Sun, X. M. Gu and P. M. Hazzledine, Phys. Rev. B: Condens. Matter Mater. Phys., 2002, 65, 220103.

47 Q. Huang, N. Baluc, Y. Dai, et al., J. Nucl. Mater., 2013, 442, S2-S8.

48 Y. Wu, Z. Chen, L. Hu, et al., Nat. Energy, 2016, 1, 16154.

49 X. Mao, K. H. Oh, S. H. Kang, T. K. Kim and J. Jang, Acta Mater., 2015, 89, 141-152.

50 M. J. Hÿtch, E. Snoeck and R. Kilaas, Ultramicroscopy, 1998, 74, 131-146.

51 L. F. He, J. Shirahata, T. Nakayama, T. Suzuki, H. Suematsu, I. Ihara, Y. W. Bao, T. Komatsu and K. Niihara, Scr. Mater., 2011, 64, 548-551.

52 M. Abolhassani and M. Mirzaei, Appl. Opt., 2007, 46, 79247926. 